\title{
Development of a Master Health Facility List in Nigeria
}

\author{
Authors: Olusesan Ayodeji Makinde ${ }^{1}$, Aderemi Azeez $^{2}$, Samson Bamidele ${ }^{1}$, Akin Oyemakinde $^{2}$, \\ Kolawole Azeez Oyediran ${ }^{3}$, Wura Adebayo ${ }^{2}$, Bolaji Fapohunda ${ }^{3}$, Abimbola Abioye ${ }^{2}$, Stephanie \\ Mullen $^{3}$
}

1. MEASURE Evaluation/ John Snow Inc., 90 Nelson Mandela Street, Asokoro, Abuja Nigeria

2. Federal Ministry of Health, Federal Secretariat Complex, Shehu Shagari Way, Abuja, Nigeria.

3. MEASURE Evaluation/ John Snow Inc. 1616 N Fort Myer Dr, Arlington, VA, United States 22209

\begin{abstract}
Introduction: Routine Health Information Systems (RHIS) are increasingly transitioning to electronic platforms in several developing countries. Establishment of a Master Facility List (MFL) to standardize the allocation of unique identifiers for health facilities can overcome identification issues and support health facility management. The Nigerian Federal Ministry of Health (FMOH) recently developed a MFL, and we present the process and outcome.

Methods: The MFL was developed from the ground up, and includes a state code, a local government area (LGA) code, health facility ownership (public or private), the level of care, and an exclusive LGA level health facility serial number, as part of the unique identifier system in Nigeria. To develop the MFL, the LGAs sent the list of all health facilities in their jurisdiction to the state, which in turn collated for all LGAs under them before sending to the $\mathrm{FMOH}$. At the $\mathrm{FMOH}$, a group of RHIS experts verified the list and identifiers for each state.
\end{abstract}

Results: The national MFL consists of 34,423 health facilities uniquely identified. The list has been published and is available for worldwide access; it is currently used for planning and management of health services in Nigeria.

Discussion: Unique identifiers are a basic component of any information system. However, poor planning and execution of implementing this key standard can diminish the success of the RHIS.

Conclusion: Development and adherence to standards is the hallmark for a national health information infrastructure. Explicit processes and multi-level stakeholder engagement is necessary to ensuring the success of the effort.

Keywords: Health Facilities, Health Information Systems, Master Facility List, Registries, Standards, Unique Identifiers

Correspondence: sesmak@gmail.com

DOI: 10.5210/ojphi.v6i2.5287

Copyright @2014 the author(s)

This is an Open Access article. Authors own copyright of their articles appearing in the Online Journal of Public Health Informatics. Readers may copy articles without permission of the copyright owner(s), as long as the author and OJPHI are acknowledged in the copy and the copy is used for educational, not-for-profit purposes. 


\section{Introduction}

Information and communications technology (ICT) has promising potential to improve routine health data management in developing countries [1,2]. However, lack of political commitment, uncoordinated efforts, and poor planning of a health information system (HIS) can cause setbacks, waste resources, and hinder and/or eventually lead to abandonment of the system [3]. Realizing the benefits of ICT in the management of routine health data will require a systems thinking approach and mental models not previously thought of [4-6]. Over the last decade, several Routine Health Information Systems (RHIS) in developing countries have been moved to electronic platforms [7-9]. However, evaluations of these electronic systems have resulted in mixed findings; e.g. some findings provided evidence for the promise of the system, while others suggested failure of the system [3].

Adoption of and subsequent migration from paper-based systems to electronic platforms will, however, present new challenges [10,11]. For instance, an identification crisis in the information system may occur. Thus, it is necessary to establish processes that will ensure system integrity and scalability are maintained and fostered. A coordinated effort should incorporate a systems thinking approach, an enterprise-wide view and broad-based planning, which includes the selection and incorporation of standards in developing the electronic information system, called for by the World Health Organization in the $66^{\text {th }}$ assembly resolution on "e-health" [12].

A required standard is a unique identification process of health facilities that will report into the information system. Identification processes may be complex; for example, in Nigeria, the governance structure delegates responsibility to 37 state-level registries, which are further supported by 774 local government institutions. If efforts are uncoordinated and each level of government develops its own process for identifying health facilities which may be similar to another state and potentially result in the same identifier issued to more than one health facility, or a starkly different process, such could make an enterprise-wide system not viable (for instance, if one state uses text characters and the other uses integers to classify health facilities). While these are potential challenges to creating an electronic platform, early planning is necessary to develop a successful electronic RHIS.

Therefore, the role of unique identification within an information system cannot be underestimated [13-16]. In terms of identifiers, different ideologies argue either for or against using intelligent unique identifiers [17]. Using intelligent identifiers, the codes allotted convey information, while non-intelligent unique identifiers are system-generated numbers/text characters which reference another table for the meaning and do not convey information in its face value [17].

In Nigeria, the Federal Ministry of Health (FMOH) has begun adopting electronic applications for the management of routine health data and applies best practices to ensuring success of the effort $[18,19]$. For this transition, the FMOH has ensured standards are met; in which one of the essential standards was developing an identification process that assigns unique National Provider Identifiers (NPIs) to health facilities nationwide. This process ultimately resulted in documenting a comprehensive Master Facility List (MFL).

Various facility lists have independently existed for decades at the FMOH, State Ministry of Health (SMOH), and Local Government Area (LGA) offices. However, in recent years, there has been an effort to centralize and coordinate these registries. Emphasis for a significant shift has 
stemmed from growing adoption of information technology (IT) in routine health information management in Nigeria, and the need to address numerous challenges in order to realize the benefits of e-health applications. Therefore, in 2010, the FMOH initiated coordination efforts to update the national health facility list, which was completed in 2013. This improved version incorporates a new dimension to the health facility identification process. The MFL was used as a platform to allocate unique identifiers to each health facility, following an intelligent coding system applicable across all states and LGAs.

In Nigeria, there are 36 states and the Federal Capital Territory (FCT). Each state is further divided into LGAs. The governance structure in Nigeria (Table 1) delegates responsibility of health facility registration to the SMOH. Thus, each state and the Federal Capital Territory had independent processes for registering and assigning identifiers to the facilities; in which each state had authority to develop the processes for assigning and updating health facility identifiers. Under the system, development of a national electronic RHIS was a difficult task. In some states, though the lists of the health facilities were available, there were actually no systematic processes for identification. To create the MFL, these 37 registries had to be used by the FMOH to cumulate the current health facility lists and to develop a systematic process to allocate new unique identifiers and eliminate any duplication.

Table 1: Levels of Governance in Nigeria

\begin{tabular}{ll}
\hline Governance Level & Oversight Function in HIS \\
\hline Federal Government & Leads the development of policies, tools, standards and \\
& guidelines, and provide technical support to the sub-national \\
government and audit the quality of data from each state. & Lead state-level coordination efforts; print and distribute tools \\
State Governments & to LGAs; collates and analyzes data for the state; provide \\
& echnical support to the LGAs; audit the quality of data \\
& national RHIS. House the Hospitals Management Board \\
& which accredits and registers new health facilities. \\
& Lead LGA level coordination effort; distribute tools to the \\
health facilities; train and provide technical support to health \\
facility records staff; and audit the quality of data emanating \\
from the health facilities. Nigeria has 774 LGAs.
\end{tabular}

MFLs are essential components of a HIS; which, according to some experts, are considered the foundation of public health [20]. A responsive HIS is composed of several sub-systems which are more meaningful when linked, rather than as stand-alone systems. The MFL provides an opportunity to link the sub-systems in a national HIS architecture. For example, a Human Resource Information System maintains data on the number of healthcare providers in a health facility, while the District Health Information System (DHIS) contains routine encounter data for the health facility. The linkage between these two sub-systems using the NPIs can provide critical data on health facilities; for instance, where the Physician/ Patient or Nurse/ Patient ratio is low which would require resource redistribution. If coordinated, a comparison can feasibly be conducted to identify areas of over-allocation and under-allocation by state or nationally, which supports evidence-based resource distribution. Overburdened healthcare providers can significantly impact the quality of care at health facilities [21,22], therefore this should be monitored and if needed, changes made to ensure quality of health care is maintained. These Online Journal of Public Health Informatics * ISSN 1947-2579* http://ojphi.org * 6(2):e184, 2014 
challenges, among others, can be addressed through coordinated HIS at national and sub-national levels.

Establishing a financial information system can provide the necessary resource data, which has been repeatedly echoed to often be unreliable in several developing countries [23]. These systems can be modeled to mirror the National Health Accounts (NHA) framework, which is regarded as the international standard for health resource tracking [24]. The potential linking of resource data, routine encounter data, and human resource data using the NPI can provide an objective analysis of resource expenditure and the associated effect in populations, in addition to informing health resource allocation and policy decisions.

Furthermore, since the NPIs will remain permanently with a health facility, it provides the ability to track the health facility data in the event of a change in name. For longitudinal studies, this is significantly important to ensure linking of data collected over time. Longitudinal studies are the hallmark for identifying causality [25], and the MFL will be an essential resource for studies on health facilities or their immediate environment.

Additionally, the MFL proposes the inclusion of geographic coordinates as part of the record for each health facility. Geographic coordinates are needed to answer the "where" question for epidemiologists investigating disease outbreaks. John Snow, an influential epidemiologist, in his landmark research in London in 1854 determined that cholera cases were linked to water supply by demonstrating the proximity of reported cases and associated mortalities to specific water pumps after developing maps to show clustering of cases [26,27]. Applying this principle to health facility data analysis can help identify areas of an outbreak and take measures to control them. In event of an undesirable clinically associated occurrence like high early neonatal mortality in a geographic region observed from routine health data, such can spur further investigation on the quality of obstetric and immediate newborn care in that area. Triangulation of data such as this can help drive change and improve the quality of care in health facilities as part of an established review of health outcomes.". The availability of geographic coordinates and the type of health services offered in each health facility in the MFL can also inform objective investment in the building or upgrading of facilities. The proximity of facilities providing needed services can be analyzed, and the need for additional health facilities may be determined based on the target population.

Availability of routine health data in an electronic database enables the development and incorporation of Decision Support Systems (DSS) that can alert investigators whenever there is a deviation from the norm [28]. This can help improve the speed of response to outbreaks and adverse events, and in addition, improve the detection rates when variations are mild, which could otherwise be overlooked. Swift response can reduce the impact of these outbreaks through the reduction in case fatality and associated morbidities. The MFL can also be used for other needs, which are summarized below:

- Application in the Health Insurance Sector

Nigeria has a fledgling national health insurance program, in which application of the NPI will be a significant standard. The NPIs will facilitate the integration and interoperability of proprietary software used for financial data management in health facilities, with the application the insurance program uses in claims 
management. Such connections can improve efficiency in the processes and the speed of claims management.

- Utilization in Research

With access to the comprehensive list of health facilities, researchers and program managers can use the MFL as a sampling frame for heath facility assessment and research.

- Unique Patient Identifier System

Further development of the NPI for patient-level identification may provide a unique patient identification system. While maintaining patient confidentiality, this could provide access to health records in a nationally, interoperable Electronic Health Record system.

In this paper, we describe how this MFL documentation was conducted; the limitations of the MFL; and what we hoped to achieve with the development of the MFL. We believe that the basic processes and standards described will provide evidence and lessons learned for other countries adopting electronic routine health information systems.

\section{Methods}

Several consultations were held among stakeholders to determine how to optimally generate the unique NPI. It was agreed that the NPI follow a systematic coding process which embeds various characteristics in the generation of the intelligent identifiers (described in Table 2). A NPI for each facility was developed by concatenating a state code, LGA code, health facility type code, health facility ownership status code, and a unique health facility serial number for the LGA. This ensured that no two health facilities have the same codes across states. Each unique identifier was made of 10 characters (written as "AABBCDEEEE"). An intelligent identification system was chosen over a non-intelligent system so that the identifiers convey basic information to users. Since several processes in the transmission of routine health data in Nigeria remain paper-based, it was anticipated that an intelligent identifier system will also convey important information to HIS specialists using the paper-based data system. Though the intelligent system was selected for use, concerns were raised on the sustainability of the MFL, should additional states or LGAs be created. However, no new LGA or states have been established for over 17 years, and hopefully this will remain. It is also expected that if a health facility changes its level of care, or there is a change in ownership class, a new NPI would be obtained according to the guidelines. In this situation, the original NPI would be discontinued. Yet, these may be limitations of this intelligent system if facilities frequently change their statuses.

The process for the collation of the health facility list followed a bottom-top approach. States were requested to compile and send a comprehensive list of health facilities within their locality to the FMOH (inclusive of the criteria described in Table 2). The FMOH created a criteria template in Microsoft Excel and state-specific workbooks. These state workbooks were prepopulated with state and LGA standard codes previously developed and utilized by the National Bureau of Statistics (NBS) and National Population Commission (NPC) before distribution to the states (refer to Table 3). For quality assurance, multiple columns were created to collect data which included the actual status of a facility before generating the corresponding code; for example, it was necessary to indicate that a health facility is a primary health facility before 
entering "1" in another column). States in turn contacted and liaised with the LGAs within their geographic coverage to collate this list inclusive of the criteria from the FMOH. The step-by-step processes of data collection and submission to the FMOH are described in Figure 1.

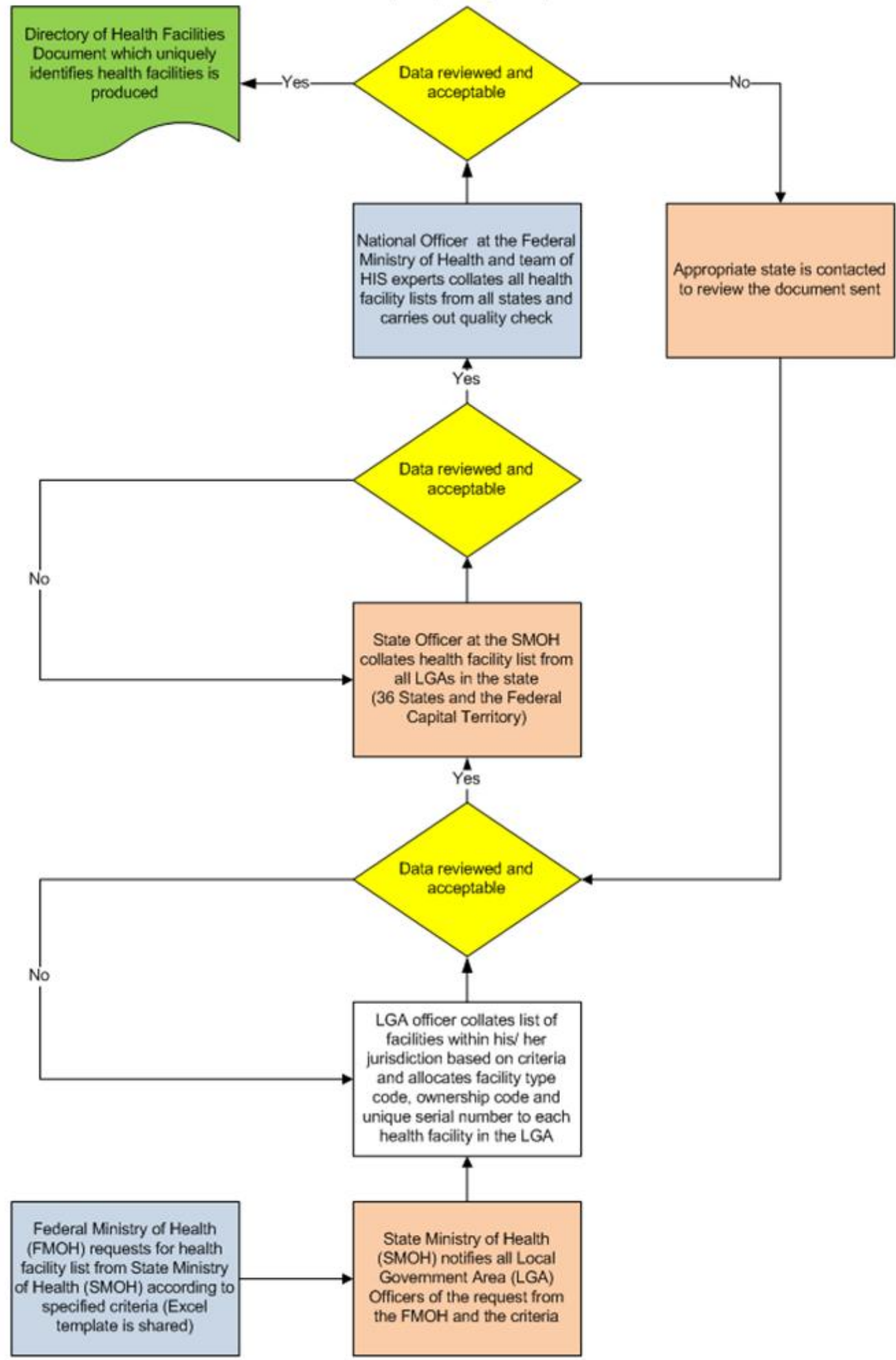

Figure 1: Collation process for the Master Facility List

Online Journal of Public Health Informatics * ISSN 1947-2579 * http://ojphi.org * 6(2):e184, 2014 
Table 2: Parameters in the unique NPI

\begin{tabular}{lll}
\hline Code Area & Description & Character Length \\
\hline State & $01-37$ & 2 characters (AA) \\
LGA & $01-44^{*}$ & 2 Characters (BB) \\
Health Facility Ownership & (1) Public [2] Private & 1 Character (C) \\
Health Facility Type & (1) Primary [2] Secondary [3] tertiary & 1 Character (D) \\
Unique LGA level Serial & $0001-9999$ & 4 Characters (EEEE) \\
Number & & \\
\hline
\end{tabular}

* The upper limit varied in each state by the number of LGAs in that state.

Table 3: An illustrative populated template used for data collection

\begin{tabular}{|c|c|c|c|c|c|c|c|c|c|}
\hline \multicolumn{10}{|c|}{ EKITI STATE } \\
\hline \multicolumn{10}{|c|}{ HEALTH FACILITY LIST } \\
\hline \multirow[t]{2}{*}{ LGA } & \multirow[t]{2}{*}{ WARD } & \multirow{2}{*}{$\begin{array}{l}\text { NAMES OF } \\
\text { HEALTH } \\
\text { FACILITY }\end{array}$} & \multirow{2}{*}{$\begin{array}{c}\text { FACILITY } \\
\text { TYPE }\end{array}$} & \multirow[t]{2}{*}{ OWNERSHIP } & \multicolumn{5}{|c|}{ CODE } \\
\hline & & & & & 点 & 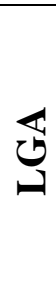 & 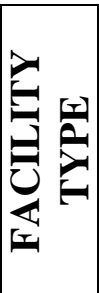 & $\begin{array}{l}\theta \\
\frac{\theta}{2} \\
\frac{1}{2} \\
\frac{1}{2} \\
\frac{1}{2}\end{array}$ & 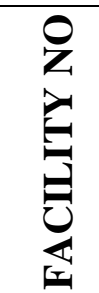 \\
\hline $\begin{array}{l}\text { Ado } \\
\text { Ekiti }\end{array}$ & \multirow{6}{*}{ Okesa } & Prison Clinic & Primary & Public & 13 & $\begin{array}{l}0 \\
1\end{array}$ & 1 & $\mathbf{1}$ & 0001 \\
\hline $\begin{array}{l}\text { Ado } \\
\text { Ekiti }\end{array}$ & & Police Clinic & Primary & Public & 13 & $\begin{array}{l}0 \\
1\end{array}$ & 1 & 1 & 0002 \\
\hline $\begin{array}{l}\text { Ado } \\
\text { Ekiti }\end{array}$ & & XTS Sch Clinic & Primary & Public & 13 & $\begin{array}{l}0 \\
1\end{array}$ & 1 & 1 & 0003 \\
\hline $\begin{array}{l}\text { Ado } \\
\text { Ekiti }\end{array}$ & & $\begin{array}{l}\text { XTS Girls } \\
\text { clinic }\end{array}$ & Primary & Public & 13 & $\begin{array}{l}0 \\
1\end{array}$ & 1 & 1 & 0004 \\
\hline $\begin{array}{l}\text { Ado } \\
\text { Ekiti }\end{array}$ & & $\begin{array}{l}\text { Joe Jane } \\
\text { Medical Center }\end{array}$ & Secondary & Private & 13 & $\begin{array}{l}0 \\
1\end{array}$ & 2 & 2 & 0005 \\
\hline $\begin{array}{l}\text { Ado } \\
\text { Ekiti }\end{array}$ & & $\begin{array}{l}\text { Adedoyin } \\
\text { Hospital }\end{array}$ & Secondary & Private & 13 & $\begin{array}{l}0 \\
1\end{array}$ & 2 & 2 & 0006 \\
\hline $\begin{array}{l}\text { Ado } \\
\text { Ekiti }\end{array}$ & \multirow{2}{*}{$\begin{array}{l}\text { Odo- } \\
\text { Ado }\end{array}$} & $\begin{array}{l}\text { Odo Ado } \\
\text { Health Center }\end{array}$ & Primary & Public & 13 & $\begin{array}{l}0 \\
1\end{array}$ & 1 & 1 & 0007 \\
\hline $\begin{array}{l}\text { Ado } \\
\text { Ekiti }\end{array}$ & & $\begin{array}{l}\text { Grace of Hope } \\
\text { Hospital }\end{array}$ & Secondary & Private & 13 & $\begin{array}{l}0 \\
1 \\
\end{array}$ & 2 & 2 & 0008 \\
\hline
\end{tabular}

The NBS and NPC developed the state and LGA codes, which were adopted nationally and ranged from ' 01 ' to ' 37 ' representing the 36 states and the Federal Capital Territory. The health facility ownership is allocated a ' 1 ' for public health facilities and ' 2 ' for private health facilities. In addition, the unique identifier includes a number for the type/level of care, where ' 1 ' is 
indicated for primary health facilities, '2' for secondary health facilities, and ' 3 ' for tertiary health facilities. The last four characters are for the LGA-level health facility serial number. Since LGAs are relatively small, it is unlikely that an LGA will exhaust the 9,999 health facilities that the four characters have the ability to accommodate. The LGA officers assigned serial numbers to the health facilities in his/her territory and the appropriate code based on the new guidelines. Upon completion, the templates were submitted to the SMOH, which in turn collated all the LGAs within their geographic area before submitting to the FMOH. At the $\mathrm{FMOH}$, quality assurance was implemented to ensure that there were no duplicate unique identifiers. In addition, the quality checks verified each of the assigned codes for the state, LGA, health facility ownership, and the level of care for each facility was correctly allocated based on the criteria.

\section{Results}

Over 34,000 health facilities were issued unique identifiers during this process. There were $11,395(33 \%)$ private health facilities and 23,028 (67\%) government health facilities. In total, $30,345(88 \%) ; 3,993(11.6 \%)$; and $85(0.25 \%)$ facilities were primary, secondary, and tertiary health facilities, respectively. The distribution of the health facilities by the state and level of care is described in Table 4.

\section{Discussion}

\section{The Future of the Master Facility List}

With a vision for a national HIS that is equipped with accessible and available information necessary for planning and monitoring the health system in Nigeria, the MFL has a promising future. An enterprise approach to improving the national HIS is recommended to maximize the gains of applying ICT to health data management [2,5]. The NPIs will serve as the unique key for identifying health facilities across the different HISs envisioned by the FMOH. The subsystems that will collectively comprise the Nigerian HIS include: the routine HIS, human resources information system, logistics management information system, and the health finance information system among others. These components can be developed as standalone information systems, with the expectation of an eventual integration. This integration capacity is important with the increasing availability of open source applications that can address the different HIS aspects. Leveraging the growing number of open-source applications created by software developers and international donors, such as the Human Resources Information System (iHRIS) created by the U.S. Agency for International Development-funded Capacity Plus Project and DHIS developed by the University of Oslo, development and adoption of standards (such as the NPI) that will facilitate the integration and interoperability of these applications is critical. This could significantly reduce the cost of deploying a national HIS [29], which could be considerable. Standards must be incorporated to facilitate the scalability of the system in a phased manner. Furthermore, Nigerian health facilities are increasingly adopting electronic medical records (EMR) for routine patient information management. The ability of these EMRs to export aggregate data into the national HIS will further strengthen it. Thus, development of the system to identify and classify health facilities across multiple information systems will lay the foundation for a national HIS revolution and the success of a scalable platform. 
Table 4: Distribution of health facilities across Nigerian states

\begin{tabular}{|c|c|c|c|c|}
\hline \multicolumn{5}{|c|}{ Type of Facility } \\
\hline State & Primary & Secondary & Tertiary & $\begin{array}{l}\text { Grand } \\
\text { Total }\end{array}$ \\
\hline Abia & 519 & 95 & 1 & 615 \\
\hline Abuja (FCT) & 559 & 90 & 7 & 656 \\
\hline Adamawa & 998 & 28 & 1 & 1027 \\
\hline Akwa Ibom & 356 & 186 & 1 & 543 \\
\hline Anambra & 1360 & 123 & 2 & 1485 \\
\hline Bauchi & 1010 & 22 & 2 & 1034 \\
\hline Bayelsa & 172 & 58 & 1 & 231 \\
\hline Benue & 1111 & 94 & 1 & 1206 \\
\hline Borno & 421 & 52 & 1 & 474 \\
\hline Cross River & 597 & 135 & 2 & 734 \\
\hline Delta & 805 & 102 & 2 & 909 \\
\hline Ebonyi & 516 & 48 & 3 & 567 \\
\hline Edo & 870 & 48 & 6 & 924 \\
\hline Ekiti & 395 & 62 & 2 & 459 \\
\hline Enugu & 524 & 342 & 2 & 868 \\
\hline Gombe & 508 & 22 & 1 & 531 \\
\hline Imo & 808 & 527 & 2 & 1337 \\
\hline Jigawa & 595 & 16 & 2 & 613 \\
\hline Kaduna & 1524 & 33 & 4 & 1561 \\
\hline Kano & 1142 & 39 & 2 & 1183 \\
\hline Katsina & 1463 & 32 & 1 & 1497 \\
\hline Kebbi & 380 & 31 & 1 & 412 \\
\hline Kogi & 869 & 208 & 1 & 1078 \\
\hline Kwara & 567 & 172 & 1 & 740 \\
\hline Lagos & 1785 & 460 & 7 & 2252 \\
\hline Nasarawa & 874 & 33 & 2 & 909 \\
\hline Niger & 1567 & 16 & 2 & 1585 \\
\hline Ogun & 1372 & 145 & 3 & 1520 \\
\hline Ondo & 769 & 39 & 3 & 811 \\
\hline Osun & 1030 & 61 & 4 & 1095 \\
\hline Oуо & 763 & 470 & 4 & 1236 \\
\hline Plateau & 835 & 47 & 1 & 883 \\
\hline Rivers & 417 & 54 & 5 & 476 \\
\hline Sokoto & 668 & 43 & 2 & 713 \\
\hline Taraba & 1030 & 14 & 1 & 1045 \\
\hline Yobe & 466 & 28 & 1 & 495 \\
\hline Zamfara & 698 & 20 & 1 & 719 \\
\hline Grand Total & 30345 & 3993 & 85 & 34423 \\
\hline
\end{tabular}


The collaborative effort between the states and LGAs made the documentation of the MFL possible. The need for this standard was jointly agreed as a step towards improving routine health information management. Additionally, several assessments highlighted the need for improved routine health data management and coordinated efforts [30-32]. One solution to improve the RHIS is to use an electronic platform in the transmission of the data. Lessons from countries that implemented similar activities emphasize the need for standardization and proper coordination of activities [18,33,34].

To promote sustainability and continued registration and generation of identifiers for new health facilities, training and development of guidelines for creating NPIs and updates to the MFL are needed. State and LGA officers need to be empowered and have clear understanding on the processes for continuously updating the MFL.

Though the first level of development of the MFL has been for health facilities (i.e. hospitals and clinics), extending the list to laboratories and pharmacies is necessary to link them into the national HIS infrastructure. These are important health institutions that provide essential information for the planning and monitoring of population health. Planning for their inclusion in the national HIS at an early stage is necessary.

\section{Information System Development}

Since there can be a leading " 0 " for the first character in the NPI, information system designers/ developers are advised to create this variable to store string or text in order to maintain the 10 character length. This field should be created as an indexed field without duplicates and possibly made the "Primary Key" of the database. It will be a fundamental field in the different information systems that are envisioned to activate the health information revolution in Nigeria. Health programs also storing facility-level data are advised to use the NPI as the primary key in their program information systems, in order for the databases to be feasibly integrated.

\section{Limitations of the MFL}

Since the idea and development of the MFL, evolution of the activities has shown some limitations in its initial design and implementation. These are important lessons for other countries preparing for similar interventions.

The activity was designed as a "snapshot", without processes for continuously updating the list. As a result, the MFL has been static since it was compiled. Thus, the FMOH has identified the need for the development of guidelines that will facilitate updates, as needed, of the registers at the LGA- and state-levels. The guidelines will encompass processes to be followed when health facility changes; for instance, if a health facility upgrades from a primary to a secondary health facility, or a secondary to tertiary health facility; and if a health facility changes ownership from private to public (or vice versa).

Another key challenge identified was that an electronic application had been previously deployed for the management of routine health facility data before the development of the standardized MFL. This electronic application utilized system-generated unique identifiers that were nonintelligent and not desirable to all stakeholders. Matching health facilities to the unique codes developed has posed challenges as there is no exact common field in the two databases, which resulted in a manual matching process. Frequently, spelling errors in one database or name changes made the matching process more difficult. Therefore, it is important to create the

Online Journal of Public Health Informatics * ISSN 1947-2579 * http://ojphi.org * 6(2):e184, 2014 
standard prior to implementation of an electronic application. Additionally, it is necessary to develop processes for updating the MFL at the onset of the project as facilities continue to be built, change status, or close.

\section{Conclusion}

Unique identifiers are necessary for any database architecture. A well-designed process for their generation and maintenance must be incorporated in the planning stages of national HIS development efforts. Countries adopting electronic routine information systems must develop and prioritize standards, such as the MFL, before system roll out. In addition to health facilities, other health institutions, such as laboratories and pharmacies, need to be considered when issuing NPIs, as they provide useful health data. The increasing availability of open-source electronic applications creates new channels for routine health information management in developing countries. These will help improve public health practices by increased data availability and transparency that, when utilized, can improve evidence-based decision making. Adopting standards that will facilitate the integration and interoperability of different subsystems of a national HIS, as available, will ensure the relevance and sustainability of the information system.

\section{Acknowledgements}

We appreciate the effort of all Federal, State and LGA officers who contributed to the completion of this MFL effort. Without them, the MFL would not have been possible. We also appreciate the effort of Ms. Heather Pitorak who helped to review an earlier draft of the manuscript and provided feedback for its improvement.

\section{Financial Disclosure}

Authors working for MEASURE Evaluation were funded to support the Federal Ministry of Health by the United States Agency for International Development (USAID) under Cooperative Agreement Number: GHA-A-00-08-00003-00.

\section{Competing Interests}

None

\section{References}

1. Braa J, Kanter AS, Lesh N, Crichton R, Jolliffe B, et al. Comprehensive yet scalable health information systems for low resource settings: a collaborative effort in Sierra Leone. AMIA Annual Symposium Proceedings [Internet]. 2010 [cited 2013 Dec 1]. p. 372. Available from: http://www.ncbi.nlm.nih.gov/pmc/articles/PMC3041283/

2. Stansfield S, Orobaton N, Lubinski D, Uggowitzer S, Mwanyika H. The Case for a National Health Information System Architecture; a Missing Link to Guiding National Development and Implementation. Mak EHealth Connect Bellagio [Internet]. 2008 [cited 2013 Dec 1]; Available from: http://wwwlive.who.int/entity/healthmetrics/tools/1HMN_Architecture_for_National_HIS_2 0080620.pdf 
3. Kossi EK, Sæbo JI, Titlestad OH, Tohouri RR, Braa J. Comparing strategies to integrate health information systems following a data warehouse approach in four countries. Proceedings of the 10th Annual International Conference on Social Implications of Computers in Developing Countries, Dubai, UAE, May Dubai School of Government [Internet]. 2009 [cited 2013 Dec 1]. Available from: http://www.uio.no/studier/emner/matnat/ifi/INF3290/h10/undervisningsmateriale/Comparin gStrategiesForHISintegration.pdf

4. Senge PM, Sterman JD. Systems thinking and organizational learning: Acting locally and thinking globally in the organization of the future. Eur J Oper Res [Internet]. 1992 [cited 2013 Dec 1];59(1):137-50. Available from: http://www.sciencedirect.com/science/article/pii/037722179290011W

5. Detmer DE. Building the national health information infrastructure for personal health, health care services, public health, and research. BMC Med Inform Decis Mak [Internet]. 2003 Jan 6 [cited 2013 Dec 13];3(1):1. Available from: http://www.biomedcentral.com/1472-6947/3/1/abstract

6. Mirza N, Reynolds TL, Coletta M, Suda K, Soyiri I, et al. Steps to a Sustainable Public Health Surveillance Enterprise. Online J Public Health Inform [Internet]. 2013 Jun 30 [cited 2014 Jan 26];5(2). Available from: http://journals.uic.edu/ojs/index.php/ojphi/article/view/4703

7. Asangansi I. 2012. Understanding HMIS Implementation in a Developing Country Ministry of Health Context - an Institutional Logics Perspective. Online J Public Health Inform. 4(3). PubMed http://dx.doi.org/10.5210/ojphi.v4i3.4302

8. Braa J, Macome E, Mavimbe JC, Nhampossa JL, da Costa JL, et al. A Study of the Actual and Potential Usage of Information and Communication Technology at District and Provincial Levels in Mozambique with a Focus on the Health Sector. Electron J Inf Syst Dev Ctries [Internet]. 2001 Aug 1 [cited 2013 Nov 30];5(0). Available from: https://www.ejisdc.org/ojs2./index.php/ejisdc/article/view/27

9. Chaulagai CN, Moyo CM, Koot J, Moyo HB, Sambakunsi TC, et al. Design and implementation of a health management information system in Malawi: issues, innovations and results. Health Policy Plan [Internet]. 2005 Nov 1 [cited 2013 Nov 30];20(6):375-84. Available from: http://heapol.oxfordjournals.org/content/20/6/375

10. Douglas GP, Killam WP, Hochgesang MS, Deula RA, Limbe W, et al. Improving completeness, accuracy \& timeliness of HIV voluntary counseling \& testing client data in Malawi using touchscreen computers. AMIA Annu Symp Proc AMIA Symp AMIA Symp [Internet]. 2005 Jan;942-942.

11. Makinde OA, Ezomike CF, Lehmann HP, Ibanga IJ. Lessons learned in the deployment of a HIV counseling and testing management information system on a new project. AIDS Lond Engl [Internet]. $2011 \quad$ Nov;25(18):2289-93. Available from: http://www.ncbi.nlm.nih.gov/pubmed/21971359

12. WHO | Sixty-sixth World Health Assembly closes with concern over new global health threat [Internet]. WHO. [cited 2014 Jan 10]. Available from: http://www.who.int/mediacentre/news/releases/2013/world_health_assembly_20130527/en/ 
13. Office of the Secretary, HHS. Administrative simplification: adoption of a standard for a unique health plan identifier; addition to the National Provider Identifier requirements; and a change to the compliance date for the International Classification of Diseases, 10th Edition (ICD-10-CM and ICD-10-PCS) medical data code sets. Final rule. Fed Regist. 2012 Sep 5;77(172):54663-720. PubMed

14. Clarke R. Human Identification in Information Systems: Management Challenges and Public Policy Issues. Inf Technol People [Internet]. 1994 Dec 1 [cited 2013 Dec 13];7(4):6$37 . \quad$ Available from: http://www.emeraldinsight.com/journals.htm?articleid=883434\&show=abstract

15. Pickens S, Solak J. 2005. National Provider Identifier (NPI) planning and implementation fundamentals for providers and payers. J Healthc Inf Manag JHIM. 19(2), 41-47. PubMed

16. Centers for Medicare \& Medicaid Services. 2004. HHS. HIPAA administrative simplification: standard unique health identifier for health care providers. Final rule. Fed Regist. 69(15), 3433-68. PubMed

17. Green B, Bide M. Unique Identifiers: a brief introduction [Internet]. Book Industry Communication \& EDItEUR; 1996 [cited 2013 Dec 1]. Available from: http://www.bic.org.uk/files/pdfs/uniquid.pdf

18. Ministry of Medical Services, Ministry of Public Health and Sanitation. Master Facility List Implementation Guide [Internet]. Available from: http://www.ehealth.or.ke/public/Master_Facility_List_-_Implementation_Guide.pdf

19. World Health Organization. Creating a Master Health Facility List [Internet]. 2012 Mar. Available from: http://www.who.int/healthinfo/systems/WHO_CreatingMFL_draft.pdf

20. Abouzahr C, Boerma T. Health information systems: the foundations of public health. Bull World Health Organ [Internet]. 2005 Aug [cited 2013 Nov 30];83(8):578-83. Available from: http://www.ncbi.nlm.nih.gov/pmc/articles/PMC2626318/

21. Lankshear AJ, Sheldon TA, Maynard A. Nurse staffing and healthcare outcomes: a systematic review of the international research evidence. Adv Nurs Sci [Internet]. 2005 [cited 2014 Mar 18];28(2):163-74. Available from: http://journals.lww.com/advancesinnursingscience/Abstract/2005/04000/Nurse_Staffing_an d_Healthcare_Outcomes_A.8.aspx

22. Shirom A, Nirel N, Vinokur AD. 2006. Overload, autonomy, and burnout as predictors of physicians' quality of care. J Occup Health Psychol. 11(4), 328-42. PubMed http://dx.doi.org/10.1037/1076-8998.11.4.328

23. Berman PA. National Health Accounts in Developing Countries: Appropriate Methods and Recent Applications. Health Econ [Internet]. 1997 Jan 1 [cited 2014 Mar 18];6(1):11-30. Available

from: http://hinarilogin.research4life.org/uniquesigonlinelibrary.wiley.com/uniquesig0/doi/10.100 2/(SICI)1099-1050(199701)6:1<11:AID-HEC238>3.0.CO;2-7/abstract

24. Powell-Jackson T, Mills A. A review of health resource tracking in developing countries. Health Policy Plan [Internet]. 2007 Nov 1 [cited 2014 Mar 18];22(6):353-62. Available from: http://heapol.oxfordjournals.org/content/22/6/353 
25. Jewell NP, Hubbard A. Analysis of Longitudinal Studies in Epidermiology [Internet]. Crc; $2006 \quad$ [cited 2014 Mar 18]. Available from: http://ehs.sph.berkeley.edu/hubbard/longdata/webfiles/chapter1.pdf

26. Cameron D, Jones IG. John Snow, the Broad Street Pump and Modern Epidemiology. Int J Epidemiol [Internet]. 1983 Jan 1 [cited 2014 Mar 18];12(4):393-6. Available from: http://ije.oxfordjournals.org/content/12/4/393

27. John Snow - The First Epidemiologist [Internet]. Public Health. [cited 2014 Mar 18]. Available from: http://blogs.plos.org/publichealth/2013/03/11/john-snow-the-firstepidemiologist/

28. Forgionne GA, Gangopadhyay A, Adya M. Cancer surveillance using data warehousing, data mining, and decision support systems. 2000 [cited 2014 Mar 19]; Available from: http://epublications.marquette.edu/mgmt_fac/76/

29. Fitzgerald B, Kenny T. Open Source Software the Trenches: Lessons from a Large-Scale OSS Implementation. ICIS [Internet]. 2003 [cited 2013 Dec 13]. p. 316-26. Available from: http://pdf.aminer.org/000/326/499/open_source_software_the_trenches_lessons_from_a_lar ge_scale.pdf

30. Makinde OA, Umar C, Adeleke O, Ohadi EM, Dieng A, et al. Assessment of the Routine Health Management Information System in Niger State, Federal Republic of Nigeria [Internet]. Bethesda, MD: Abt Associates Inc.; 2012 Sep. Available from: http://www.healthsystems2020.org/content/resource/detail/92757/

31. Makinde OA, Adebayo SB, Adeleke O, Ohadi EM, Dieng A, et al. Assessment of the Routine Health Management Information System in Taraba State, Federal Republic of Nigeria. [Internet]. Bethesda, MD: Abt Associates Inc.; 2012 Sep. Available from: http://www.healthsystems2020.org/content/resource/detail/92753/

32. Makinde OA, Ohadi EM, Adeleke O, Umar C, Dieng A, et al. Assessment of the Routine Health Management Information System in Kebbi State, Federal Republic of Nigeria. [Internet]. Bethesda, MD: Abt Associates Inc.; 2012 Sep. Available from: http://www.healthsystems2020.org/content/resource/detail/92759/

33. Coffey RM, Ball JK, Johantgen M, Elixhauser A, Purcell P, et al. The case for national health data standards. Health Aff (Millwood) [Internet]. 1997 [cited 2013 Dec 15];16(5):5872. Available from: http://content.healthaffairs.org/content/16/5/58.short

34. 1998. National standard health care provider identifier--HCFA. Proposed rule. Fed Regist. 63(88), 25320-57. PubMed 